\title{
Do as I Do: Physician- and Learner-Led Mind-Body Medicine Group Visits
}

Elwyn Moir, MMH | Jamie O. Yang, BS | Jimmy Yao, BA | Eva Weinlander, MD

PRiMER. 2021;5:4.

Published: 2/1/2021 | DOI: 10.22454/PRiMER.2021.548093

\section{Abstract}

Introduction: Care of patients with chronic medical and mental health conditions can be a source of frustration for primary care clinicians and may present a challenge in modeling effective interventions for medical learners. Mind-body medicine (MBM) interventions have shown success for a variety of conditions, and training in MBM has been associated with decreased burnout and improved professional satisfaction. ${ }^{8}$ We piloted MBM collaborative visits led by faculty physicians and facilitated by medical learners. We then assessed their efficacy treating patients with complex needs.

Methods: We conducted a series of eight weekly 2.5-hour MBM interventions for groups of five to eight participants (52 in total) with chronic health conditions. Matched-pair hypothesis $t$ tests analyzed nine health indicators measured pre- and postintervention: the Patient Health Questionnaire-9 (PHQ-9) as well as participants' perceived mental and physical health, stress and stress coping, agency, and capacity to connect with others. We made conservative calculations of effect size using Hedges' $g$.

Results: Participants showed significant, large improvements in their PHQ-9 scores $(P<.005, g=0.807)$, and moderate improvements in ability to cope with stress $(P<.005, g=0.502)$, sense of control over their diagnoses $(P<.05, g=0.413)$, and perceived overall mental health $(P<.05, g=0.424)$. Other outcomes were nonsignificant, including a small improvement in participants' perceived overall health $(P=.071, g=0.286)$.

Conclusions: Patients completing the intervention enjoyed largely improved outcomes despite unchanged stress at work and home. Physician-led MBM collaborative visits comprise a feasible, reproducible, and reimbursable treatment option for improving patient care. They also immerse medical learners in an evidence-based practice model supportive of professional satisfaction.

\section{Introduction}

Chronic conditions, often refractory to treatment, frustrate patients and physicians alike ${ }^{1,2}$ and present challenges in modeling effective interventions for learners. ${ }^{3}$ Environmental and behavioral conditions also have outsized effects on health. ${ }^{9}$ Mind-body medicine (MBM) connects our thoughts, feelings, behaviors, and physiology to their effects on overall health. MBM collaborative visits involve small, physician-led groups that improve patient self-care by teaching skills for physiological and behavioral self-regulation. From parasympathetic engagement to mindful eating, these skills benefit patients living with a variety of chronic diseases. ${ }^{4-7}$ 
Teaching these skills distinguishes MBM from interventions like mindfulness-based stress reduction (MBSR), which uses mindfulness to defuse ruminations and cognition habits that reinforce anxiety or depressed mood. ${ }^{10}$ MBSR is less concerned with changing the content of beliefs and other frameworks of perceptions than the more global MBM approach. While MBM utilizes mindfulness, it also uses variable channels of expression and exploration to equip the individual with alternative frameworks for managing unhelpful patterns, empowering patients with the agency to change them. ${ }^{11}$ Emerging research supports neurobiologic and genomic effects from these practices. ${ }^{12}$ The Center for Mind Body Medicine in Washington, DC trains physicians in these techniques (biophysical feedback systems, genograms, etc) and in the process and curriculum for facilitating group visits.

Group programs designed to increase patient agency in managing their health conditions have shown success. Lorig, et al conducted a large study-with some overlap in content to ours-of their Chronic Disease SelfManagement Program (CDSMP). ${ }^{13}$ They examined outcomes and cost savings associated with their 7-week, 2.5 hours/week, community-based, peer-led, self-management program for those over 40 years of age with chronic heart disease, lung disease, stroke, or arthritis. They focused on the adoption of exercise programs, use of cognitive techniques such as guided relaxation and distraction, and achieving positive change in areas of diet, sleep, use of medication and resources, and health-related problem solving and decision making.

Physician professional satisfaction is an ongoing research imperative. Burnout is linked to disempowerment in the work environment, whereas meaningful, unhurried doctor-patient relationships support professional satisfaction. ${ }^{2}$ Of Linzer's Ten Bold Steps to prevent physician burnout, ${ }^{14}$ MBM collaborative visits further three: reserving time for preferred work activities, incorporating mindfulness and teamwork into practice, and prioritizing self-care as part of medical professionalism. Training in facilitating MBM skills groups is associated with decreased burnout and increased quality of life. ${ }^{8}$ With challenging patients in mind, Edgoose and colleagues found protective effects for physicians who employed the structured "BREATH OUT" mindfulness and preparedness process before difficult appointments. ${ }^{15}$

Acknowledging the frustration associated with refractory conditions, we engaged patients experiencing stress and chronic conditions (such as pain and mental health concerns) using an intervention of MBM collaborative visits led by a faculty physician assisted by premedical scribes, two of whom are now medical students. We assessed the efficacy of this intervention by change in PHQ-9 scores and measures of stress, stress-coping, perceived control, and connectedness.

\section{Methods}

Between 2014 and 2019, primary care and specialist physicians within our academic institution's health care system referred 52 patients with chronic pain, psychiatric, and other conditions (Table 1) to join a series of eight weekly MBM sessions ( 2.5 hours per session) led by a faculty family physician certified in MBM and assisted by a premedical learner scribe. With guidance from our institution, all visits included a brief, individual face-to-face before convening for collaborative visits, the combination of which were billable to insurance at the 99213 level. Visits featured a shared general structure (Table 2): opening meditation, presentation of mind-body topics (Table 3), practice of self-regulatory skills, and facilitated group sharing. Assessing these sessions comprised a clinical quality improvement project and was exempt from institutional review board review.

Before the first visit and immediately after the last, participants completed five-item Likert scales including perception of overall mental health, ability to handle stress, sense of control over their condition, impact of their diagnosis on their health, personal/work stress, physical health, and ability to connect with others. We composed the Likert questions (Table 4) to ask participants about the causes of their stress. When one of the authors (then a learner cofacilitator) noticed increasing prevalence of depressed mood, we introduced the 
PHQ-9 in later cohorts for its validated sensitivity (88\%) and specificity (85\%) in detecting affective disorder and monitoring treatment progress. ${ }^{16,17}$

We tracked participants' scores using anonymized identifiers and included measures of life stressor intensity to distinguish treatment effect versus extratherapeutic changes. We collected deidentified free-response written feedback from participants and the premedical learners (after their engagement with the study) for qualitative analysis. Our analysis of the qualitative data included a review for themes and patterns in feedback and response, and identifying any striking or particularly representative expressions of ideas within the feedback. We analyzed data by matched-pair hypothesis $t$ tests. In light of the small sample size of this pilot, to quantify effect size, we used the Hedges' $g$ measure, which is more conservative than Cohen's $d$.

\section{Results}

Matched-pair hypothesis $t$ tests and Hedges' $g$ analysis of pre- and postintervention data (Table 4) demonstrate a significant, large improvement in participant PHQ-9 scores $(P<.005, g=.807)$ and moderately improved selfperceptions of overall mental health $(P<.05, g=0.415)$, ability to handle stress $(P<.005, g=0.502)$, and ability to exert control over their diagnoses $(P<.05, g=0.413)$. Physical health improvements were small and fell short of statistical significance $(P=.071, g=0.286)$. These improvements manifested despite participants reporting no significant changes in their diagnosis perception $(P=.088, g=0.204)$, ability to connect with others $(P=.51$, $g=0.134)$, or level of stress in their personal $(P=0.46, g=0.059)$ and work $(P=.55, g=0.0139)$ environments. The box-plot in Figure 1 illustrates the lower median and interquartile range for postintervention PHQ-9 scores relative to baseline. Variations in measure applicability to participants (eg, not all worked or had mental health diagnoses) restricted certain sample sizes. Full written feedback from the premedical learners is provided in Table 5 along, with some quoted participant feedback.

\section{Discussion}

MBM collaborative visits were followed by improvements in participant well-being and preparedness to manage their chronic health conditions. Participants showed significant improvement in PHQ-9 and Likert assessments of self-perceived mental health, capacity to cope, and empowerment to manage symptoms. They shared, for example, that they had "never felt that kind of connection in a group," now saw themselves as "stronger than [I] thought," and that they "now have tools to handle situations in a calmer way." One participant wrote "I feel I have my anxiety in check as long as I am mindful of it. I am sleeping better and longer" (Table 5).

Given the decreased burnout and improved quality of life for health care providers participating in MBM professional training, ${ }^{8}$ this study suggests MBM collaborative visits may create a meaningful patient-physician connection that benefits both the patient's quality of care and the physician's professional satisfaction. Additionally, the visits model a self-care intervention that premedical learners may carry with them into their careers. Our learners shared that, through participating and cofacilitating, they saw the value of the techniques: efficacy, applicability to their own lives, applicability to their own patients, and as a template for facilitation exercises in medical school.

Participant outcomes improved without perceived change in stress in their personal or working lives, notable given Lambert's landmark finding that at least one-third of psychotherapy outcome appears to result from extratherapeutic changes. ${ }^{18,19}$ While extratherapeutic stress levels remained constant, the PHQ-9 mood effects were large, and participant-perceived agency and stress-coping improved moderately as well. Findings of improved health status and agency echo those of Lorig's CDSMP study which, although also without an immediate control group, found participants enjoyed reduced health distress, increases in perceived efficacy, lower health care utilization, and no unexpected worsening of health status or disability in the subsequent 12 
months.

While we accounted for extratherapeutic effects, absence of a control group precludes attributing causality to the MBM visits. Either a delayed treatment group or another intervention of well-known efficacy (eg, individual psychotherapy) could serve as a future control. Small numbers and insufficient opportunity for long-term observation preclude identifying the effect involving premedical students has on their future practice. We would like to understand whether their facilitation of these MBM visits leads to incorporating novel approaches protective of physician satisfaction in their future practices, along with downstream effects on patient care quality or their own well-being. With the advent of the COVID-19 pandemic creating risk for in-person visits, we began a new study trialing videoconference collaborative visits in April 2020. Given the preponderance of anxiety concerns among our participants, our new study includes the validated GAD-7 measure for anxiety.

Following our MBM intervention, participants with a range of chronic medical and psychiatric conditions enjoyed large improvements in mood and moderately improved health-related agency outcomes despite unchanged levels of stress at work and home. Physician-led, learner-facilitated MBM collaborative visits comprise a practical and insurance-billable treatment suitable for improving patient self-management and coping skills in a busy primary care practice, while enhancing the doctor's patient contact time in a format supportive of physician professional satisfaction. The visits also model an effective intervention for future medical professionals.

\section{Tables and Figures}

Table 1: Relative Frequencies of Most Common Medical Concerns and Symptoms Motivating Patient Participation in the MBM Collaborative Visits of This Study

\begin{tabular}{|l|c|}
\hline \multicolumn{1}{|c|}{ Reason for MBM Visits } & \multicolumn{1}{c|}{ Percentage of Participants } \\
\hline Stress/anxiety & 32 \\
\hline Chronic pain & 14 \\
\hline Management of weight and diabetes & 11 \\
\hline Insomnia & 6 \\
\hline
\end{tabular}

Abbreviation: MBM, mind-body medicine.

Table 2: General Process of an MBM Collaborative Visit

\begin{tabular}{|l|l|}
\hline \multicolumn{1}{|c|}{ Sequence of an MBM Collaborative Visit } & \multicolumn{1}{|c|}{ Active Roles } \\
\hline Patients checked in individually and privately by physician & Physician working with scribe \\
\hline Opening meditation & Physician or scribe \\
\hline Group members check-in & $\begin{array}{l}\text { Patients take turns to update group on their well-being, } \\
\text { progress and insights. Physician and scribe model and } \\
\text { facilitate. }\end{array}$ \\
\hline $\begin{array}{l}\text { Explanation of a mind-body technique, and group practice with the } \\
\text { technique }\end{array}$ & Physician \\
\hline Group sharing of participants experience practicing the technique & $\begin{array}{l}\text { Patients take turns to provide feedback and insights. } \\
\text { Physician and scribe model and facilitate. }\end{array}$ \\
\hline Explanation of homework & Physician \\
\hline Closing meditation & Physician or scribe \\
\hline
\end{tabular}

Abbreviation: MBM, mind-body medicine 
Table 3: Outline of Weekly Curriculum of the 8-Week Intervention

\begin{tabular}{|c|c|c|}
\hline Week & MBM Focus Topic & Key Associated Activities \\
\hline 1 & $\begin{array}{l}\text { Introduction and three } \\
\text { drawings }\end{array}$ & $\begin{array}{l}\text { Establishment of group norms/expectations } \\
\text { Three drawings: "how you feel/see yourself now"; "yourself with your main problem"; } \\
\text { "how you would be if the problem was solved." }\end{array}$ \\
\hline 2 & Autogenics and biofeedback & Biofeedback exercise using thermal biofeedback and autogenic phrases \\
\hline 3 & General meditation & Concentrative, mindfulness, and active meditations \\
\hline 4 & $\begin{array}{l}\text { Imagery and guided } \\
\text { meditations }\end{array}$ & Introduction to "safe place" and "wise guide" imagery/meditations \\
\hline 5 & Emotions & Dialogue with an emotion, problem, illness \\
\hline 6 & Mindful eating & $\begin{array}{l}\text { Mindful eating exercise (small fruit/berry) } \\
\text { Mindful eating: habits, taste, hunger, satiety }\end{array}$ \\
\hline 7 & Genograms & $\begin{array}{l}\text { Development and exploration of patterns of strengths, weaknesses, and sources of } \\
\text { support within the family tree/genogram. }\end{array}$ \\
\hline
\end{tabular}

\section{Table 4: Instruments and Questions With Specified Likert Scales, Measured Change $(\Delta)$, and Effect Size Calculated as Hedges' $g$}

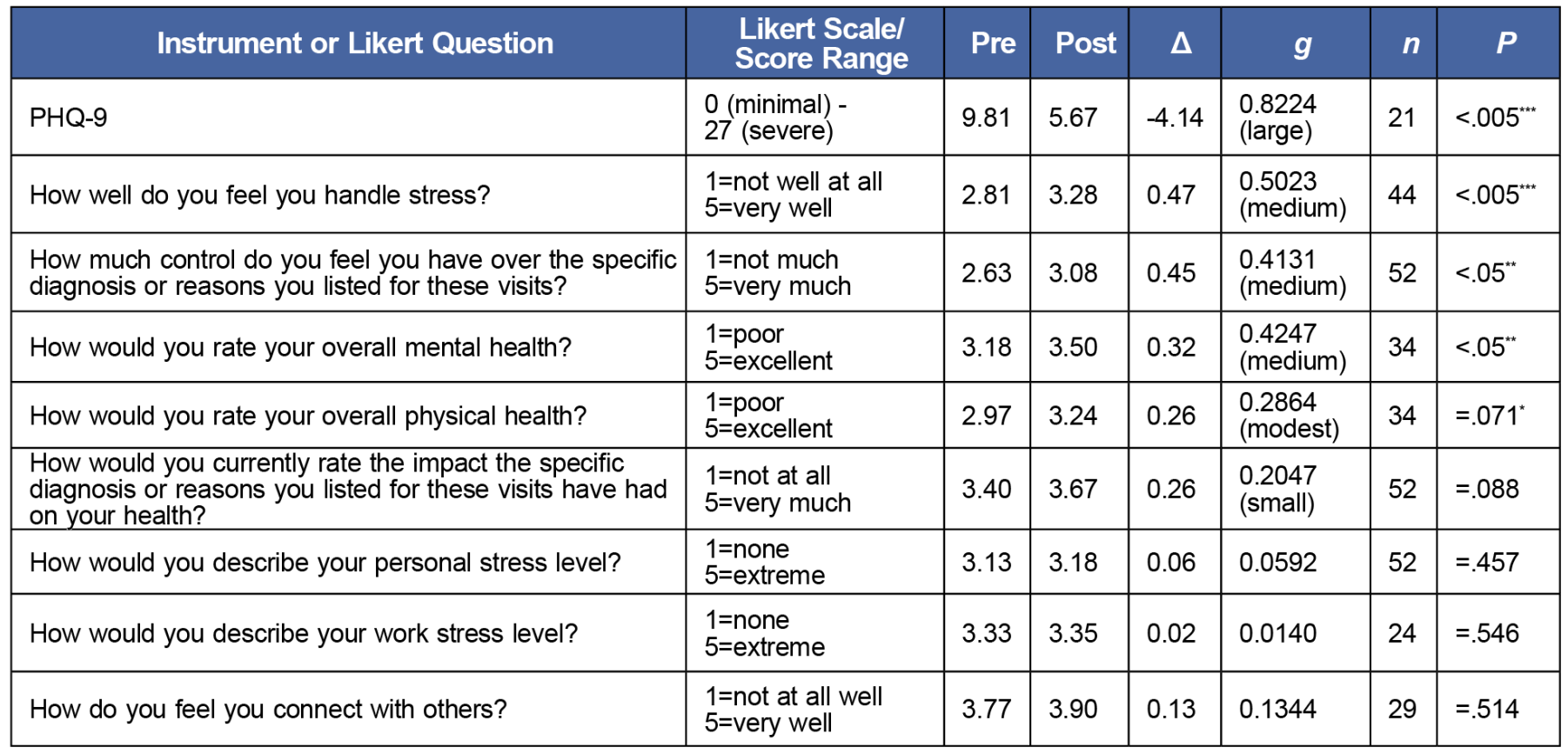

Abbreviation: PHQ-9, Patient Health Questionnaire-9.

Certain pre- and posttreatment measures (eg, employment status, mental health diagnosis) were inapplicable for some study participants, yielding varying sample size by measure. PHQ-9 measures were introduced for the later study cohorts. 


\section{Figure 1: Box Plots of Patient PHQ-9 Scores Before and Immediately Following Completion of the MBM Collaborative Visits ( $P<.005$ for Change in Scores Post- vs Preintervention)}

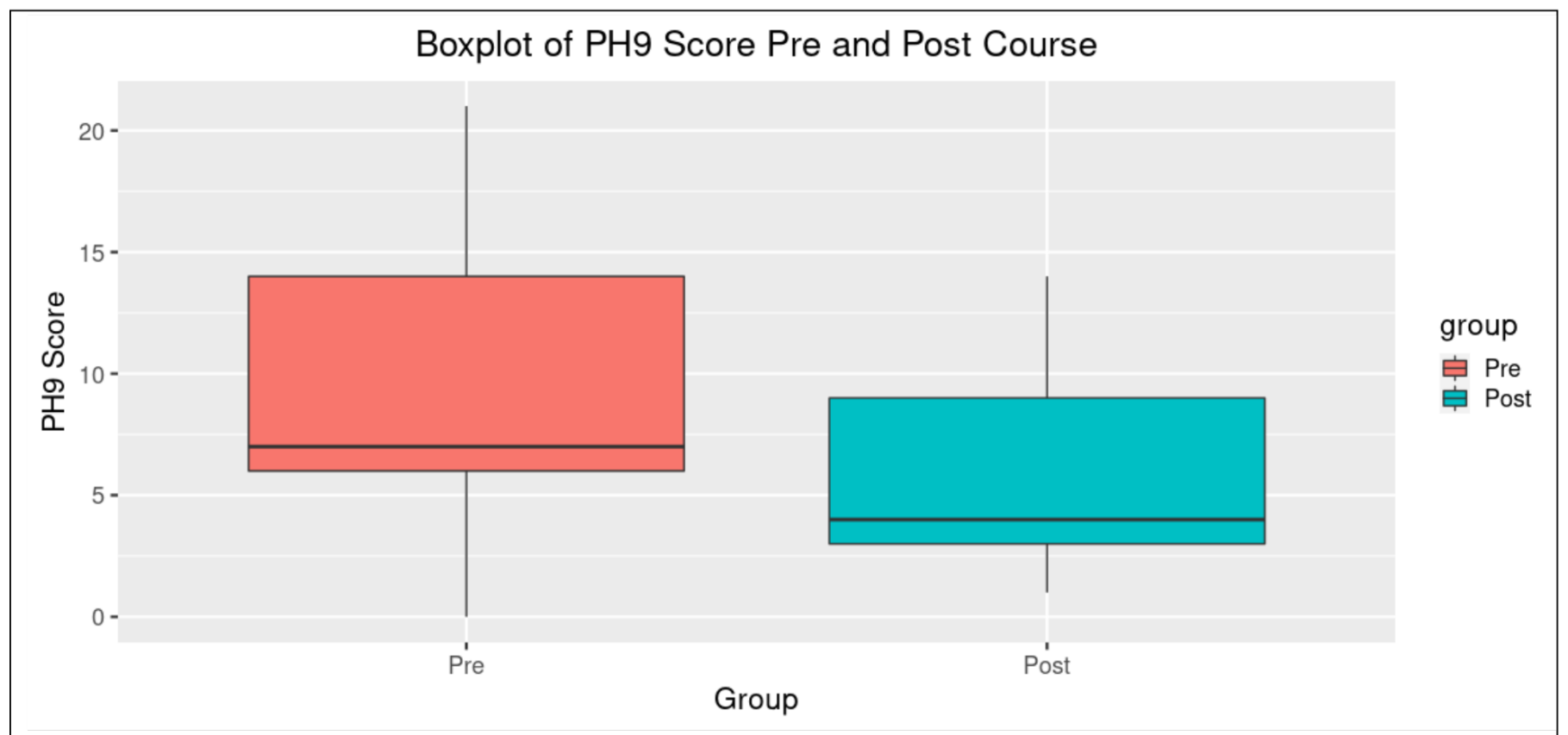

Table 5: Complete Text of Free-Response Comments From Premedical Cofacilitators, and Select Study Participant Feedback Quoted in This Paper

\begin{tabular}{|c|c|}
\hline Comment Author & Comment (Full Text) \\
\hline Participant & I feel I now have tools to handle situations in a calmer way. \\
\hline Participant & $\begin{array}{l}\text { Surprisingly, I am coping better with my stress level-I feel as though I have my anxiety in check as long } \\
\text { as I am mindful of it. I am sleeping better and longer. }\end{array}$ \\
\hline Participant & $\begin{array}{l}\text { The "surprise"/valuable part of the group WAS the group. I had NEVER felt that kind of connection in a } \\
\text { group. It was SO accepting and then connections developed so naturally. }\end{array}$ \\
\hline Premedical learner & $\begin{array}{l}\text { Being involved with the MBM visits showed me the true efficacy of mind body medicine techniques in } \\
\text { calming the mind, and in doing so healing the physical body in a way that could be just as effective as } \\
\text { prescribing medications. Learning these techniques have been useful tools on my journey to becoming } \\
\text { a doctor. Using body scans, I am able to calm my mind and fall asleep after a busy day. I can use deep } \\
\text { breathing to calm my nerves before presenting in front of a group. I can advise my patients that I meet } \\
\text { about different meditation apps and relay an understanding of the utility of meditation and how it can help. } \\
\text { Seeing how it positively impacted the patients who took the MBM course made me inspired and convinced } \\
\text { to not only practice it in my own life, but also to recommend it in the future to my patients. }\end{array}$ \\
\hline Premedical learner & $\begin{array}{l}\text { There were a few takeaways I kept for myself after being a "assistant facilitator" for the MBM collaborative } \\
\text { visits. For example, I always kept in mind the need to take a deep breath before entering a simulated } \\
\text { patient encounter exam, and whenever I needed to calm down after a long busy day, I would always } \\
\text { remember to practice some deep breathing. Other points I kept in mind included mindful eating so I didn't } \\
\text { under- or overeat. Lastly, the structure of the collaborative visits was useful to me since I helped facilitate } \\
\text { group visits ("shared-medical appointments") for the management of other chronic diseases (eg, diabetes) } \\
\text { during my family medicine rotation! }\end{array}$ \\
\hline Premedical learner & $\begin{array}{l}\text { No matter what we're told, a large part of learning what to do and how to be a physician comes from what } \\
\text { we see happening. It's reassuring to see a professional think about how to do their job in smart way that } \\
\text { allows them to feel great about doing it. The MBM meetings were deeply experiential, so it's easy to feel } \\
\text { the effectiveness of some of the techniques right away. That leaves me with a clear memory of what's } \\
\text { possible in self-care, and not just an abstract idea. While I don't yet know what it means for me in the long } \\
\text { run, participating in the MBM visits has broadened my perspective on how to view medicine in practice. }\end{array}$ \\
\hline
\end{tabular}

Abbreviation: MBM, mind-body medicine

\section{Acknowledgments}

Presentations: Select findings in this manuscript were presented at the STFM Conference on Practice Improvement, December 1, 2017, in Louisville, Kentucky. 


\section{Corresponding Author}

Elwyn Moir, MMH

elwyn@sfsu.edu

\section{Author Affiliations}

Elwyn Moir, MMH - Certified Medical Scribe, Stanford Family Medicine

Jamie O. Yang, BS - David Geffen School of Medicine at University of California, Los Angeles, CA

Jimmy Yao, BA - Case Western Reserve University School of Medicine, Cleveland, $\mathrm{OH}$

Eva Weinlander, MD - Division of Primary Care, Department of Medicine, Stanford University School of Medicine, Stanford, CA

\section{References}

1. Goldsmith ES, Krebs EE. Roles of physicians and health care systems in "difficult" clinical encounters. AMA J Ethics. 2017;19(4):381-390. doi:10.1001/journalofethics.2017.19.4.pfor1-1704

2. An PG, Rabatin JS, Manwell LB, Linzer M, Brown RL, Schwartz MD; MEMO Investigators. Burden of difficult encounters in primary care: data from the minimizing error, maximizing outcomes study. Arch Intern Med. 2009;169(4):410-414. doi:10.1001/archinternmed.2008.549

3. Holman HR. The relation of the chronic disease epidemic to the health care crisis. ACR Open Rheumatol. 2020;2(3):167-173. doi:10.1002/acr2.11114

4. Nijjar PS, Puppala VK, Dickinson O, et al. Modulation of the autonomic nervous system assessed through heart rate variability by a mindfulness based stress reduction program. Int J Cardiol. 2014;177(2):557-559. doi:10.1016/j.ijcard.2014.08.116

5. Selhub EM. Stress and distress in clinical practice: a mind-body approach. Nutr Clin Care. 2002;5(4):182-190. doi:10.1046/j.1523-5408.2002.00404.x

6. Hassed C. Mind-body therapies-use in chronic pain management. Aust Fam Physician. 2013;42(3):112-117.

7. Herman PM, Anderson ML, Sherman KJ, Balderson BH, Turner JA, Cherkin DC. Cost-effectiveness of Mindfulness-based Stress Reduction Versus Cognitive Behavioral Therapy or Usual Care Among Adults With Chronic Low Back Pain. Spine. 2017;42(20):1511-1520. doi:10.1097/BRS.0000000000002344

8. Weinlander, E.E., Gaza, E.J., Winget, M. Impact of Mind-Body Medicine Professional Skills Training on Healthcare Professional Burnout. Glob Adv Health Med. 2020;・:9-2164956120906396.

9. Schroeder SA. Shattuck Lecture. We can do better-improving the health of the American people. N Engl J Med. 2007;357(12):1221-1228. doi:10.1056/NEJMsa073350

10. Hoge EA, Bui E, Marques L, et al. Randomized controlled trial of mindfulness meditation for generalized anxiety disorder: effects on anxiety and stress reactivity. J Clin Psychiatry. 2013;74(8):786-792. doi:10.4088/JCP.12m08083

11. Toneatto T, Nguyen L. Does mindfulness meditation improve anxiety and mood symptoms? A review of the controlled research. Can J Psychiatry. 2007;52(4):260-266. doi:10.1177/070674370705200409

12. Dossett ML, Fricchione GL, Benson H. A New Era for Mind-Body Medicine. N Engl J Med. 2020;382(15):1390-139 doi:10.1056/NEJMp1917461

13. Lorig KR, Ritter P, Stewart AL, et al. Chronic disease self-management program: 2-year health status and health care utilization outcomes. Med Care. 2001;39(11):1217-1223.

doi:10.1097/00005650-200111000-00008

14. Linzer M, Levine R, Meltzer D, Poplau S, Warde C, West CP. 10 bold steps to prevent burnout in general internal medicine. J Gen Intern Med. 2014;29(1):18-20. doi:10.1007/s11606-013-2597-8

15. Edgoose JY, Regner CJ, Zakletskaia LI. BREATHE OUT: a randomized controlled trial of a structured 
intervention to improve clinician satisfaction with "difficult" visits. J Am Board Fam Med.

2015;28(1):13-20. doi:10.3122/jabfm.2015.01.130323

16. Huang FY, Chung H, Kroenke K, Delucchi KL, Spitzer RL. Using the Patient Health Questionnaire-9 to measure depression among racially and ethnically diverse primary care patients. J Gen Intern Med. 2006;21(6):547-552. doi:10.1111/j.1525-1497.2006.00409.x

17. Levis, B, Benedetti, A, Thombs, BD; DEPRESsion Screening Data (DEPRESSD) Collaboration. Accuracy of Patient Health Questionnaire-9 (PHQ-9) for screening to detect major depression: individual participant data meta-analysis. BMJ. 2019;365:I1476. doi:10.1136/bmj.I1476

18. Lambert, MK. Implications of Psychotherapy Outcome Research for Psychotherapy Integration. in J.C. Norcross, JC, Goldfried, MR, eds. Handbook of Psychotherapy Integration. New York: Basic Books; 1992 : 94-129.

19. Cuijpers P, Driessen E, Hollon SD, van Oppen P, Barth J, Andersson G. The efficacy of non-directive supportive therapy for adult depression: a meta-analysis. Clin Psychol Rev.

2012;32(4):280-29doi:10.1016/j.cpr.2012.01.003

Copyright $(\subseteq 2021$ by the Society of Teachers of Family Medicine 